\title{
JIMENA MUÑOZ, AMIGA DE ALFONSO VI
}

\author{
SUMARIO
}

A. Los casamientos de Alfonso VI - B. Jimena Muñoz, la muy noble concubina - C. Aclaraciones y conclusiones - Apéndice documental.

Alfonso VI fue rey de León y de Castilla desde 1072 a 1109 , año de su muerte. Dos años antes de morir, su padre, Fernando I, en solemne curia regia celebrada en la ciudad de León en 1063, dividió su reino entre sus tres hijos: al mayor, Sancho, atribuyó Castilla, al menor, García, concedió Galicia, y al mediano, Alfonso, «hijo predilecto», según la expresión del Silense, le otorgó la Tierra de Campos y todo el reino de León y, con ello, de un modo implícito, «el título imperial y la soberanía política» '.

Esta soberanía se hizo efectiva, una vez que el hermano mayor cayó herido de muerte ante los muros de Zamora (1072) y el menor fue encarcelado en el castillo de Luna.

Los historiadores modernos, Ballesteros Beretta, García de Valdeavellano y otros, están de acuerdo en que el reinado de Alfonso fue uno de los más gloriosos de nuestra historia patria. Por el norte se abrieron las puertas a la cultura europea, y por el sur se fueron ampliando los territorios conquistados, ampliación que culminó con la toma de la ciudad imperial de Toledo, mayo $1085^{2}$.

Esta apertura hacia la culta Europa se manifestó con la implantación de la reforma cluniacense y del rito romano en este reino, con las alianzas matrimoniales de Alfonso con princesas europeas de la más alta nobleza, con el casamiento de dos de sus hijas, Urraca y Teresa, con Roberto de Borgoña y Enrique de Lorena, respectivamente. Estas alianzas procuraron a Alfonso la fuerte ayuda de estos fieles colaboradores francos y borgoñones en la tarea de la reconquista.

Historia silense, ed. Pérez de Urbel, Madrid 1959, 204.

2 A. BAllesteros BereTta, Historia de España, Barcelona 1920, II, 537. L. GarCía de Valdeavellano, Historia de España, 5." ed., Madrid 1973, I/2, 237. 
De sus dos hijas llamadas ambas Elvira, una se casó con Ramón, conde de Tolosa, y la otra con Rogerio, rey normando de Sicilia.

Sin embargo, aunque Alfonso fue afortunado en el reino, que consolidó, amplió y "exornó», al decir del Silense, no lo fue en la prole. Sus numerosos casamientos no le otorgaron la alegría de morir dejando el cetro a un hijo varón. El cetro fue primero a manos de su hija Urraca, hija de Constanza, y luego a su nieto Alfonso, de la Casa Borgoñona.

Estos casamientos de Alfonso han sido ya varias veces analizados, con más o menos fortuna, a partir sobre todo de fray Prudencio de Sandoval. El padre Flórez intentó arrojar luz sobre este problema, pero sin mayor resultado. Y ya en nuestro siglo el padre Fita y Menéndez Pidal montaron un cliché que ha sido fielmente reproducido por los autores siguientes hasta nuestros días '.

Es indiscutible que Alfonso VI mantuvo relaciones extramatrimoniales con dos nobles damas: una castellana, llamada Jimena Muñoz, y otra mora, llamada Ceida o Zaida. Es mi propósito al presente ilustrar la identidad de esa primera mujer, Jimena, ya que una nieta suya, Teresa Fernández, fue progenitoria, junto con su marido el conde Osorio Martínez, de la Casa de los Osorio y de los Villalobos. Pero este tema de los amores de Alfonso fuera del matrimonio no se puede tratar aisladamente. Es necesario aclarar primero lo relativo a sus alianzas legítimas.

\section{A. LOS CASAMIENTOS DE ALFONSO VI}

\section{a) Águeda de Normandía, la prometida}

Es indudable que el rey de León obtuvo la mano de una joven francesa, llamada Agatha o Águeda, hija de Guillermo duque de Normandía y luego rey de Inglaterra (1066-1087), conocido comúnmente como Guillermo el Conquistador. Lo atestiguan dos historiadores fidedignos y casi coetáneos: Orderico Vitalis y Guillermo de Malmesbury.

Juan Ferreras y otros colocan estos tratos hacia 1067: esta joven sería así el primer amor del joven rey leonés, pero la data de los mismos nos es desconocida. Lo seguro es que, en una época u otra, Alfonso solicitó la mano de esta dama normanda, que le fue concedida, quizás por mediación de los monjes de Cluny, sus amigos de él. El trato se hizo sin conocerse los novios. Quizás fue este

'Sandoval, Historia, 344. Flórez, Reinas, I, 163. Fita, La Conjuración, 326. MENÉndeZ PidAl, La España del Cid, 7. ed. Madrid 1969, I, 237. 
el motivo de que ella sintiese repugnancia a emprender un viaje tan largo para casarse con un príncipe desconocido. Águeda, que era virgen, en el curso del viaje deseó morir, se lo pidió a Dios y fue escuchada. La comitiva volvió sobre sus pasos y llevó el cadáver de la joven a enterrarlo en la iglesia de Bayeux. Como se ve, esto no llegó a ser matrimonio, se redujo a un simple esponsalicio. Águeda no fue la primera mujer de Alfonso, fue sólo su prometida ${ }^{4}$.

\section{b) Inés de Aquitania, la primera mujer}

Tanto la Crónica Malleacense como el obispo Pelayo están de acuerdo en afirmar que Inés de Aquitania fue la primera mujer de Alfonso. Y esto concuerda también con la documentación. Según los diplomas de la catedral de León y el convento de Sahagún, Inés estuvo en la corte leonesa con su marido desde el 1 de julio de 1074 hasta el 8 de septiembre de 1076: dos años largos. Esto no impide que esta estancia o convivencia fuese algo más extensa'.

Inés era hija de Guido o Guillermo (usó varios nombres este personaje), que fue VI conde de Poitiers y VIII del nombre duque de Aquitania.

Al cabo de esa convivencia, ¿que pasó con Inés? ¿Murió? ¿Se divorció? Los autores españoles a partir de Sandoval afirman lo primero. Inés murió en León el año 1078 y fue sepultada en la iglesia del monasterio benedictino de Sahagún. Escribe Sandoval: «En este año (1078) a seis de junio, conforme a las memorias del Tumbo Negro de Santiago, murió la reina doña Inés». Lo mismo repite el padre Flórez ${ }^{6}$.

Los Anales Compostelanos o Efemérides Riojanas afirman en efecto que Inés murió el 6 de junio, pero del año 1097:

«Era MCXXXV (año 1097) regina Agnes VII Idus Iunii». Sin embargo, estos anales fueron redactados en época tardía y muy lejos de León para ser creídos sin más'.

${ }^{4}$ Ferreras, Historia, V, 110. Los textos de Orderico y de G. de Malmesbury en el Apéndice documental.

' RUIZ ASENCIO, Colección documental de la catedral de León, IV, p. 459 y ss. Herrero, Colección, III, p. 12 y ss.

- Sandoval, Historia, 212. FlóReZ, Reinas, I, 167.

1 Anales compostelanos, ed. Flórez, E.S., t. 23, p. 317. Uno de los mejores textos lo ofrece el códice: B.N., Mss. 1376 (s. XVI/2) fol. 369-373. Se creía que estos Anales se hallaban en el códice: Bi. R.A.H., C-75 (9/5496), del siglo XIV, que llaman «Tumbo Negro de Santiagom. Sin embargo, J.M. Fernández Catón (El llamado Tumbo colorado y otros códices de la iglesia compostelana, ensayo de reconstrucción, en Archivos leoneses, 44, 1990, 251) niega ese supuesto. Ver: GómEZ-MORENO, Discursos, Madrid 1917. 
Don Lucas de Tuy dice también que está sepultada en Sahagún al lado de la reina Constanza. Éste escribía ya en el siglo XIII y su testimonio tampoco es convincente ${ }^{8}$.

Por otro lado tenemos el testimonio del ya citado Orderico Vitalis, muy respetable, quien afirma que «el conde de Le Mans, Elías, al fallecer su esposa Matilde, con quien había convivido muchos años, contrajo nuevas nupcias con Inés, la abandonada por Alfonso, rey de Galicia. Elías celebró la boda con gran esplendor pero murió al año siguiente (1110)».

Estas palabras tienen un significado bien claro y concreto, y no podemos darles otro más sutil y falso. Las palabras "relictam Hildefonsi senioris» quieren decir que el rey la abandonó. Si leemos otros pasajes similares del mismo autor, encontraremos ese mismo significado. No podemos pues pensar en una Inés viuda ${ }^{\text {. }}$

Podemos presumir que, al ver que aquella joven francesa, que con él había vivido unida en matrimonio desde los quince años de edad hasta los diecisiete, no le daba hijos, pensó en la anulación del mismo enlace y la celebración de uno nuevo. Todo quizás en buena fe. Y la despidió. Ella esperó a que su antiguo marido muriese (1109) para unirse a un nuevo esposo. Veremos que algunos hechos subsiguientes confirman esta presunción.

\section{c) Constanza de Borgoña, segunda mujer}

Es la segunda mujer señalada por el obispo Pelayo, y la segunda documentada en la catedral de León y en el monasterio de Sahagún. Constanza aparece en la corte de León, en compañía del rey y conquistador de Toledo, desde el 8 de mayo de 1080 hasta el 2 de setiembre de $1093^{10}$.

La noble dama borgoñona debió llegar a León en la primavera de 1079. Su vida se extinguió en la misma ciudad de León o en la villa de Sahagún entre el 2 de setiembre 1093, fecha de la donación predicha, y el 22 de noviembre del mismo año, cuando su marido ofrece por su alma a la grande abadía los palacios que ella misma había mandado fabricar en Sahagún y una cruz de oro ". 50.

${ }^{8}$ LUCAS DE TUY, Cbronicon mundi, ed. Schott, en Hispania illustrata, IV, 104, 1.

9 El texto de Orderico en el Apéndice documental. De este modo piensan los padres benedictinos, autores de L'art de vérifier les dates. Otra es la opinión de Flórez (Reinas, I, 219). 101 y ss.

10 Ruiz ASencio, Colección, IV, p. 491 y ss. Herrero de la Fuente, Colección, III, p.

$"$ Herrero de la Fuente, Colección, III, p. 240, n. 914. Crónicas anónimas de Sabagún, ed. Ubieto, p. 16, n. 9. Ed. Escalona, Historia, p. 300, n. 7. 
Constanza era hija de Roberto I, duque de Borgoña (1032-1075), y llegaba a León viuda ya de Hugo, conde de Chalon-sur-Saone. Este matrimonio del rey debió ser agenciado por Roberto, amigo de la misma reina y monje de Cluny, que acababa de llegar a Sahagún, con el encargo de introducir allí la reforma benedictina.

Constanza era prima tercera de Inés, en cuarto grado de consanguinidad, como descendientes ambas de Guillermo III de Aquitania (990-1029) ${ }^{12}$.

Según lo expuesto, a Constanza deben referirse las palabras fuertes y acres que el papa Gregorio VII dirige a Alfonso VI en carta fecha el 27 junio 1080. Ella debe ser «la mujer perdida que apartó el ánimo del rey del recto camino», «la antigua favorecedora del monje Roberto». El papa reprocha a Alfonso el haber contraído "un matrimonio ilícito con una consanguínea de su mujer» (Inés). Y le dice que «un amor incestuoso cegó su alma para no escuchar los saludables consejos de la verdad" ${ }^{13}$.

Esta es la opinión, que yo estimo acertada, de varios autores: A. Herculano, P. David, Defourneaux. Y por consiguiente hay que desechar las antiguas interpretaciones ${ }^{14}$.

Para Sandoval y para Flórez esa mujer de perdición que ha pervertido el corazón de Alfonso, y con la cual él ha contraído un matrimonio ilícito, no es otra que Jimena Muñoz, la noble manceba convertida en concubina. Pero aquí existe una contradicción. Jimena, si se ha casado, ya no es concubina. Y la palabra connubium que la letra pontificia usa no tiene otro sentido: significa matrimonio, contrato nupcial. Para ellos, la reina Inés sería leonesa y Jimena sería su pariente o consanguínea ${ }^{15}$.

Fita y Menéndez Pidal, por su parte, opinan de otro modo, una vez asegurado que Inés es francesa, y por tanto sin parentesco con Jimena Muñoz. Esa mujer, perturbadora del hogar regio, para ellos sería una noble cortesana arribada de Borgoña con la misma reina Constanza, una antigua amiga del monje Roberto. Pero esto no se concilia con los hechos. Si Alfonso se casó con Constanza y ella convive con él en la corte, ¿cómo es posible que él contrajese un nuevo connubio con la anónima cortesana? ${ }^{16}$.

12 Para la filiación de Constanza: D'ANTINE, L'art de vérifier les dates, I, p. 743. DAvid, Études, 386 y ss. DefourneauX, Les Français, p. 30 y ss.

13 Gregorio VII, Epistola a Alfonso VI, en el Apéndice documental.

14 A. Herculano, Historia de Portugal, 8. ${ }^{2}$ ed. Lisboa (c. 1920), II, 229-238. David, Études, 386. DefourneauX, Les Français, 30. Añadir: ReIlLy, The Kingdom, 108-110, cuya obra conocí después de redactar este trabajo.

15 SANDOVAL, Historia de los reyes, 346, FlóREZ, Reinas, I, 222. Este último autor se ahoga en su propia erudición, sin poder discernir las pruebas correctas de las falsas o inválidas. Hace más caso de epitafios tardíos que de autores contemporáneos.

${ }^{16}$ Ver supra, n. 3. No entienden correctamente la palabra connubium, que significa matrimonio. 
Por fin nuestra opinión viene reforzada y avalada por otros dos hechos. Primero, que meses más tarde el mismo papa Gregorio VII envía otra epístola al rey leonés, ponderando su sabiduría y su humildad, agradeciendo sus regalos y remitiendo a la decisión del legado Ricardo y del obispo de Burgos, Jimeno, el asunto de su mujer y lo relativo a la abadía sanfacundense ${ }^{17}$.

Podemos de ahí conjeturar que el rey presentó ante el pontífice solicitud de anulación matrimonial y la respuesta fue confiada a esos dos eclesiásticos.

El segundo hecho es que, muertas su segunda y tercera esposas, es decir Constanza y Berta, el rey ofrece por sus almas en la célebre abadía sendas cruces de oro, como precisan el Anónimo de Sahagún y los diplomas regios. Lo mismo hubiera hecho por las siguientes esposas, Isabel y Beatriz, si el tiempo se lo hubiera permitido. Su prematura muerte de él se lo impidió. Pero nada de esto se verifica respecto a su primera esposa: del amor y de la muerte de Inés no nos queda en León ningún recuerdo serio. Su marido no se acuerda de ella. ¿Por qué? Casi seguro, porque ella se había ido ${ }^{18}$.

\section{d) Las otras mujeres legitimas: Berta, Isabel, Beatriz}

Lo relativo a estas tres últimas mujeres de Alfonso VI interesa menos para nuestro propósito. Apuntemos sin embargo algunos detalles. Se dice que Berta está ya en la corte en noviembre 1093. No me consta de modo cierto. En la documentación de León y de Sahagún aparece desde el 28 de abril 1095 hasta el 17 noviembre 1099.

Su nombre es variable: Berta, Huberta, Alberta. No dio hijos al rey. El obispo Pelayo afirma que era oriunda de la Tuscia (Lombardía, Piemonte, Toscana??) ${ }^{19}$.

La cuarta mujer legítima, según el obispo Pelayo, fue Isabel, madre de Sancha, casada con el conde Rodrigo González de Lara, y de Elvira, casada con Rogerio, rey de Sicilia.

Sandoval pone dos reinas con el nombre de Isabel: una hija del rey moro de

17 Para mayor comodidad, esta segunda carta la puede ver el lector bien publicada en: SANDOVAL, Historia, 352.

18 El 25 enero 1100 Alfonso VI dona a Sahagún, por el alma de su esposa Berta, el monasterio de San Salvador de Valdevidriales (Zamora): HERRERO DE LA FUENTE, Colección, III, p. 384, n. 1045. El Anónimo dice que Berta murió el año 1099, y menciona la donación citada y la de una cruz de oro (ed. Ubieto, p. 17).

19 Ruiz ASENCio, Colección, IV, p. 606 y ss. Herrero de la FUente, Colección, III, p. 286 y ss. 
Sevilla (la Zaida) y otra hija de Luis, rey de Francia, «como reza el epitafio de San Isidoro de León" ${ }^{20}$.

Esta segunda Isabel habrá que eliminarla, ya que parece fruto de la leyenda y su epitafio no merece fe alguna. Por tanto quedamos sólo con la hija del rey de Sevilla, con la Zaida, que una vez bautizada recibió el nombre cristiano de Isabel. Su nombre Elisabeth está documentado en la catedral de León y en la abadía de Sahagún desde el 31 de julio de 1101 hasta el 17 de noviembre $1108^{21}$.

La quinta mujer legítima fue Beatriz, que figura sólo una vez en los diplomas de la catedral de León, el 1 de enero de 1109, es decir, cuatro meses antes de la muerte del rey. Don Pelayo silencia su origen, mientras el Toledano la hace francesa.

\section{B. JIMENA MUÑOZ, LA MUY NOBLE CONCUBINA}

El obispo don Pelayo no sólo consignó fielmente el nombre de las cinco

20 SANDOVAl, Historia, 344 y ss.

${ }^{21}$ Ruiz ASENCIO, Colección, IV, p. 633 y ss. Herrero DE LA Fuente, Colección, III, p. 429 y ss. Sobre la Ceida o Zaida: E. LEVI-PROVENÇAL, La mora Zaida femme d'Alphonse VI de Castille, en «Hespéris» (Paris), 18 (1934) 1-8, 200-201. R. MENÉNDEZ PIDAL, La España del Cid, 762 y ss.

Tanto Levi-Provençal como Menéndez Pidal tienen por seguro que las relaciones entre Alfonso VI y la mora Zaida tuvieron inicio hacia 1091 . Y yo no veo dificultad en admitir que el fruto de esas amorosas relaciones, el infante Sancho, naciera entre 1092 y 1095 . De ese modo, al morir en la batalla de Uclés, año 1109 , tendría ya unos dieciséis años.

En cambio, y estando a la afirmación del obispo Pelayo, las dos infantas Sancha y Elvira, hijas de Alfonso, y de la reina Isabel, nacerían en los primeros años del siglo XII, 1101 y siguientes. $Y$, eso, aunque ambas hermanas confirmen un acto solemne con sus padres el año 1106 en pro de la catedral de Oviedo.

Contra los asertos de los epitafios tardíos y del mismo Tudense, que se inspira ya en los cantares de gesta, hay que reconocer que Alfonso VI tuvo una sola mujer con el nombre de Isabel, y que esa mujer fue la Zaida. Así lo afirman el obispo Pelayo y la reina Urraca. Ésta, en un diploma a la iglesia de Toledo del 13 de marzo 1115: «Sicut eam (domum) habuerunt et tenuerunt regine uxores patris mei, scilicet Berta, Isabel et Beatrix». (GARCÍA LUJÁN, Privilegios reales, Toledo 1982 , II, p. 27, n. 5).

Las dos hijas de la reina Isabel (la Zaida), las infantas Sancha y Elvira Alfonso, aparecen juntas, como si fueran gemelas, en varios diplomas entre 1106 y 1116 . La segunda ya no está el año 1118, indicio de que ya había partido para Italia, donde se desposó con Rogerio II de Sicilia, conde en 1113, duque de Apulia en 1128 y rey de Sicilia en 1130. Elvira le dio cinco hijos: Tancredo, Alfonso, Rogerio, Guillermo y una hija. Murió Elvira hacia 1142 y fue enterrada en la Capilla regia de Santa Magdalena, en la ciudad de Palermo (ROMOALDO DE SALERNO, Annales, ed. MGH, SS, XIX, pp. 421-425). 
esposas legítimas de Alfonso, sino que nos dio también el nombre de las dos nobles concubinas. "Tuvo el rey también dos concubinas, pero muy nobles: la primera se llamó Jimena Muñoz, y fue madre de Elvira Alfonso, esposa de Ramón, conde de Tolosa, y de Teresa, esposa del conde Enrique (y luego reina de Portugal)» ${ }^{22}$.

La identificación familiar de doña Jimena Muñoz ha interesado poco a los historiadores castellanos, ya que sus hijas se casaron fuera de Castilla. Interesó más a los escritores portugueses por tratarse de la madre de su primera reina. Sin embargo, el padre Flórez dedicó a este tema unas cuantas páginas, siguiendo en el fondo las líneas trazadas por Sandoval. Un estudio más directo le dedicó A. Quintana Prieto, suponiendo a Jimena y a su hija Elvira nativas del Bier$\mathrm{zO}^{23}$.

No satisfecho ni con las conclusiones ni con las pruebas aportadas por esos autores, intentaré arrojar nueva luz sobre este oscuro problema, que me interesó ya hace tiempo al tratar de los orígenes de la Casa de los Osorio y de los Villalobos $^{24}$.

a) ¿Es bija del conde Munio Rodriguez?

El erudito jesuita asturiano, Alfonso de Carvallo, que escribía en los primeros decenios del siglo XVII, ya afirmó sin titubeos que Jimena Muñoz fue hija del conde Munio Rodríguez, natural y señor de Cangas de Tineo. Y dice que éste primero casó con Jimena Ordóñez, y luego con Anderquina. Del mismo sentir es el padre Flórez.

Pero, para dar una buena solución a este problema, tendremos que distinguir a los tres personajes que llevaron ese nombre en la primera mitad del siglo $\mathrm{XI}{ }^{23}$.

${ }^{22}$ Pelayo OBISPo De Oviedo, Chronica regum. Ver infra Apéndice documental, n. 5. Sobre la persona de don Pelayo y el valor de su obra: F.J. FerNánDEZ CONDE, El libro de los testamentos de la catedral de Oviedo, Roma-Burgos 1973, pp. 35-80. Pelayo fue obispo de Oviedo de 1098 a 1129. Conoció, trató y admiró a Alfonso VI. Murió el 28 enero 1153. Su testimonio es precioso.

${ }^{23}$ SANDOVAL, Historia, 344 y ss. FlóReZ, Reinas, I, 185 y ss. Este autor menciona a varios historiadores portugueses que hablan de doña Jimena Muñoz. A mediados del siglo XIX escribía: A. Herculano, Historia de Portugal, ed. 8.', II, 229-238. A. Quintana Prieto, Jimena Muñiz, madre de doña Teresa de Portugal, Coimbra 1969.

${ }_{24}$ J.M. CANALSÁNCHEZ-PAGÍn, La Infanta doña Elvira, hija de Alfonso VI y de Gimena Muñoz, León 1979.

25 Carvallo, Antigüedades, pp. 290, 309. Linajes, p. 31. En la primera obra este autor cita incorrectamente un documento de la catedral de Oviedo. El texto correcto es el 
En primer lugar está el magnate que figura en la corte de los reyes Vermudo II y Alfonso V, entre los años 998 y 1023 . Es conde en 1011 y ostenta el título de dux, o capitán del ejército, en 1012 . Poco sabemos de su persona fuera de esto. Pudiera ser el padre del conde Fermando Muñoz de Campos, que en 1043 dona a Sahagún y afirma ser hijo del conde Munio Rodríguez y de su mujer Adosinda. La misma cronología excluye que sea el padre de nuestra Jimena Muñoz.

En segundo lugar está el magnate gallego que casó con Jimena Ordóñez, la hija del infante Ordoño Vermúdez y su mujer doña Fronilde, y que fue padre del conde Rodrigo Muñoz, el que murió en la batalla de Sacralias, el año 1086. Parece ser que Munio era hijo del conde Rodrigo Romaniz y de su mujer, Elvira. Como reza un diploma de Fernando I en favor de Celanova, 19 agosto 1061, este conde Munio se rebeló contra el rey Fernando, en sus castillos de Monterroso, y perseguido por los soldados del rey huyó a los montes ${ }^{26}$.

En tercer lugar está el magnate asturiano, que casó con Enderquina Froilaz y fue padre del conde Munio Muñiz, el de la jornada de Sevilla, y de cuatro hijas. Llevaba los motes de Mayor y de Canis. Y es conocido por el Registro de Corias.

Por razón de la cronología no habría dificultad para que fuesen éstos padres de Jimena Muñoz, pero no existe razón alguna positiva que avale esta opinión. Pondré en esquema estas tres genealogías ${ }^{27}$.

siguiente: «Henricus comes cum uxore sua Tarasia imperante Tinegio» (GARCíA LARRAGUETA, Colección, p. 340, n. 128).

El padre Flórez da por buena esta filiación, y de ella deduce el parentesco de Alfonso VI con Jimena Muñoz (Reinas, I, 190).

${ }^{26}$ Creo que por razón del tiempo en que vivieron es preciso distinguir a estos dos magnates. En un documento de la catedral de León de 12 noviembre 1012, confirma: «Munnio Ruderiquiz dux» (RUIZ ASENCIO, Colección, III, p. 270, n. 709).

Podemos sospechar que Munio es hermano del conde Pelayo Rodríguez, su coetáneo, y que ambos son hijos de Rodrigo Gutiérrez, hermano del conde santo, como quiere García Álvarez ( $L a$ Infanta Fronilde, peregrina a Compostela, en "Compostellanum», 9, 1964, 180). Ver también: HeRrero DE LA FUENTE, Colección, II, p. 142, n. 477.

Sobre el segundo conde de este nombre estamos mejor informados y remito al estudio que le acaba de dedicar Salazar Acha (Los Descendientes del conde Eno Fernández, en Galicia en la Edad Media, Madrid 1990, pp. 67-86). La muerte de su hijo Rodrigo es recordada por el obispo Pelayo en su Crónica (E.S., 14, 468).

${ }^{27}$ Un documento de la catedral de Oviedo, del 28 junio 1056, en nota añadida por los escritores del Liber Testamentorum, menciona al conde Munio Rodríguez «Maior» y a sus cuatro hijas: Aldonza, Elo, Mayor, Elvira (GARCíA LARRAGUETA, Colección, p. 185, n. 58). El Registro de Corias afirma del mismo varias cosas: 1) que fundó el monasterio de Caravia, 2) que estuvo casado con Enderquina, 3) que fue padre de la condesa Aldonza la fundadora de Corias, y del conde Munio Muñiz, el de la jornada de Sevilla, 4) que llevaba el mote de Canis (Floriano, Corias, I, pp. 63, 120; II, pp. 140, 164, 209). 
A) I. Conde Munio Rodríguez, el dux (m. h. 1024) $=$ Adosinda

II. Conde Fernando Muñoz de Campos = María

III. Hijos: 1. Munio. 2. Rodrigo. 3. Pedro. 4. Adosinda Fernández

B) I. Conde Munio Rodríguez, el gallego (m. h. 1074)

$=1$. Jimena Ordóñez

$=2$. Ilduara Velásquiz

II. Hijos del 1: 1. Conde Rodrigo Muñoz (m. 1086).

2. Osorio Muñoz. Y del 2: Elvira Muñoz

C) I. Conde Munio Rodríguez, el asturiano (m. h. 1050)

= Enderquina Froilaz

II. 1. Conde Munio Muñiz, el de Sevilla (1063)

2. Aldonza Muñiz = conde Piniolo Jiménez

3. Elo Muñiz = conde Gonzalo

4. Mayor Muñiz = conde Munio Fernández

5. Elvira Muñiz = conde Fernando Muñiz

b) ¿Hija del conde Munio Muñiz, el de la jornada de Sevilla?

Es el monje de Corias, el autor del Tumbo citado, quien nos informa detalladamente sobre este personaje. Fue hijo del citado conde Munio Rodríguez el Mayor, y de su esposa Enderquina Froilaz. Se casó primero con Jimena Muñiz de Somiedo, con quien tuvo una hija llamada Jimena Muñiz, quien se casó a su vez con el conde Munio Rodríguez el Joven. Se casó él segunda vez con Mumadonna Jiménez de Asturias, con la que tuvo dos hijas: Velasquita Muñiz y Mayor Muñiz ${ }^{28}$.

Nos refiere además este autor que este conde presidió, con los obispos de León y de Astorga, la expedición que viajó a Sevilla para trasladar a la ciudad de León el cuerpo de san Isidoro (hacia 1063). El rey don Fernando I le premió

El citado Registro menciona al conde Rodrigo Muñoz, hijo del conde Munio Rodríguez, pero esto no incluye necesariamente que hayamos de identificar a ambos condes Munio, al gallego y al asturiano (Corias, I, p. 153).

${ }^{28}$ Floriano, Corias, I, 63. Es mencionado aquí otro conde con el mismo nombre: Munio Rodríguez Junior. Quizás por eso en el diploma de Oviedo es llamado el otro Maior. 
este servicio, donándole el territorio de Campo Salinas, en el valle del río Luna ${ }^{29}$.

¿Será la hija de este conde, esta Jimena Muñiz, la amiga y amada de Alfonso VI? Esto ha pensado y piensan en nuestros días varios autores. Para mí es muy difícil aceptar esta solución, por dos motivos. Primero, de ser así, no lo hubiera silenciado el monje Cauriense, tan erudito en genealogías. Segundo, veo cierta repugnancia en que la amiga del rey se desposase con otro hombre. Debería permanecer siempre célibe, por respeto y por amor a su antiguo amigo, a un amigo de tanta categoría ${ }^{30}$.

Pongamos ahora en esquema estas filiaciones:

I. Conde Munio Muñiz, el de Sevilla

$=1$. Jimena Muñiz de Somiedo

$=2$. Mumadonna Jiménez de Asturias

II. Del I matrimonio: Jimena Muñiz = conde Munio R.

Sus hijas: Velasquita y Mayor

Del II matrimonio: Velasquita Muñiz

Podemos mencionar otros condes que existieron en el siglo XI, como Munio Fernández del Valle del Esla, Muño Muñiz, teniente en Cea, Munio Alfonso de Saldaña, pero ofrecen pocas o ninguna probabilidad de ser padres de doña Jimena Muñiz.

\section{c) ¿Hija del conde Munio González de Cantabria?}

Es una filiación interesante y digna de ser discutida. Fue ya sugerida por el padre Francisco Sota, cronista de Su Majestad, en su Crónica, publicada el año 1681, aunque con pruebas insuficientes ${ }^{(31)}$.

La figura y la familia de este conde Munio de Cantabria han sido ya estudiadas y esbozadas por autores notables, como Menéndez Pidal y Balparda.

${ }^{29}$ Ibidem, 61. Para la traslación del cuerpo de san Isidoro de Sevilla a León: Historia Silense, ed. J. Pérez de Urbel, Madrid 1959, p. 199. E. FLÓREZ, E.S., t. 34, p. 86. A. VIÑAYO, La llegada de San Isidoro a León, en "Archivos leoneses», 17 (1963) 65-112.

${ }_{30}$ Opiniones sobre el padre de Jimena Muñoz: Quintana PrIETo, Jimena Muñiz, 230. Salazar ACHa, Una Familia, 33, n. 52.

${ }^{31}$ SOTA, Crónica, 542. Se apoya Sota en un documento de Sobrado, a todas luces sospechoso, falso. No se encuentra en el Tumbo conservado. ¿Se refiere Sota a alguno de los falsos cronicones que por aquel tiempo pululaban por la península, y en los cuales él tanto creía? 
Pero yo no me he interesado por ellas hasta que tuve la satisfacción de leer la donación que su hija Jimena hizo a Cluny el año 1120 de su iglesia de Santa Cruz de Castañeda. Creo que ningún autor castellano se ha detenido a examinar este interesante diploma, que existe sólo en los archivos franceses ${ }^{(32)}$.

Objeto de la donación fue el monasterio de Santa Cruz de Castañeda, situado en el actual municipio de Castañeda, partido judicial de Villacarriedo, provincia de Cantabria, a unos quince quilómetros de Torrelavega, en el valle del río Pisueña, afluente del río Pas. Hoy aún podemos admirar su hermosa iglesia románica, convertida desde hace mucho tiempo en colegiata, una de las más valiosas de la región.

Este monasterio, como precisa el mismo diploma, fue fundado hacia el año 1070 por el padre de doña Jimena, y su primer abad se llamó Juan, que aún lo gobernaba el año 1092. El año 1120, año de la expedición del dicho privilegio, lo presidía el abad Pedro. La donación del mismo a la abadía de Cluny indica que era de monjes benedictinos ${ }^{(33)}$.

Sin embargo en la lista de prioratos o abadías, dependientes de Cluny en la edad media, no es mencionado éste: señal de que, después de la muerte de Jimena, la familia lo sustrajo al dominio de la abadía francesa. Conjeturamos también que en el decurso de los siglos XII-XIII se redujo a colegiata, al estilo de otros centros monásticos de la región ${ }^{(34)}$.

Familia de la donante: Jimena Muñoz, que no menciona ni a su marido ni a sus hijos, de lo cual deducimos que era célibe, es hija del conde Munio González y de su esposa doña Mayor. Es hermana del conde Rodrigo Muñoz y tía de Mayor Roiz y Sancha Roiz, hijas del predicho conde Rodrigo. Es también parienta de la familia del conde Fernando Díaz de Oviedo, hermano presunto

${ }^{32}$ R. MENÉNDEZ PIDAL, El Romanz del Infant Garcia y Sancho de Navarra antiemperador, en Historia y epopeya, Madrid 1934, 52 y ss. G. DE BALPARDA, Historia crítica de Vizcaya, Bilbao 1974, I, 447, 473. También el padre J. Pérez de Urbel se refiere a esta familia en su Historia del condado de Castilla, Madrid 1945, 3 vols.

13 Información sobre la colegiata de Santa Cruz de Castañeda: Serrano, Obispado, II, 228. ARgáiz, Soledad, VI, 583. FlóreZ, E.S., 27, 2-10. GARCíA GUINEA, El Románico, II, 265.

Sobre el condado de Castañeda (s. XIV) ver: PÉReZ BustamanTE, Señorío, 117 y ss. No se hace alusión a los condes de la alta edad media, y menos a Jimena Muñoz.

${ }^{34} \mathrm{Ni}$ U. Robert (État des monastères) ni M. Marrier (Bibliotheca Cluniacensis) mencionan este monasterio de Castañada, en la lista de prioratos o abadías que dependían de Cluny en la edad media. Mencionan en cambio Cornellana (Asturias), San Isidro de Dueñas (Palencia), Villaverde de Vidriales (Zamora), etc.

La abadía de Cornellana se independizó más tarde y se sometió al obispo de Oviedo. 
de la mujer del Cid. Es decir que Enderquina, mujer de este conde asturiano, debia ser hermana de Jimena. Para aclarar esta genealogía pondré un esquema seguido de su explicación:

I. Conde Munio González de Álaba (siglo X) $=$ N.N.

II. Conde Gonzalo Muñoz de Asturias de Santillana $=$ N.N.

III. Conde Munio González de Cantabria (m. hacia 1085) = Mayor

IV. 1. Conde Rodrigo Muñoz de Cantabria (m. hacia 1115)

$=$ Teresa

2. Gutierre Muñoz $=$ N.N.

3. Enderquina Muñoz $=$ conde Fernando Díaz

4. Urraca Muñoz = conde Gómez González de Bureva

5. Jimena Muñoz

V. (Hija del conde Rodrigo) Mayor (Gontrodo) Roiz = conde Pedro Froilaz de Traba y de Galicia (Hija de Gutierre Muñoz) Enderquina Gutiérrez $=$ conde Suario Vermúdez, fundador de Cornellana ${ }^{(3)}$.

Como es fácil comprobar, esta genealogía está atestiguada por el privilegio de Jimena, si exceptuamos a los dos primeros condes, a Urraca Muñoz y a

35 La existencia de Gutierre Muñoz consta por un documento de Santa María del Puerto (Santoña), fecha 21 julio 1090, en el que aparece al lado de su hermano Rodrigo. Ver: Serrano SanZ, Cartulario, , p. 238, n. 55.

Los condes Fernando Díaz de Oviedo y su esposa Enderquina aparecen en la documentación de la catedral de Oviedo, en la de San Vicente de Oviedo, y en la de Belmonte (Asturias). Este conde murió hacia 1106.

Los condes Suario Vermúdez y Enderquina están quizás más documentados, aunque no tuvieron sucesión. Este conde aparece con mucha frecuencia en la corte y en los diplomas de la reina Urraca y de Alfonso VII. Es de origen gallego, como hijo del conde Vermudo Ovéquiz y su esposa Jimena Peláez. Murió el año 1138.

La filiación de su esposa Enderquina es discutida. Floriano Cumbreño la hace asturiana, hija del conde Alfonso Ordónez y Fronilde (Corias, II, pp. 65, 290). El padre Serrano (Obispado, III, p. 150, n. 81) la hace castellana, hija del magnate Gutierre Roiz, poco conocido. Salazar Acha la hace de la Casa de Castro, hija de Gutierre Fernández de Castro (Una Familia, p. 45, n. 108). Que sea hija de Gutierre Muñoz de Cantabria lo pone bien claro la donación del presbítero Gonzalo al monasterio de Oña, 8 marzo 1128 (Isabel Oceja, Documentación, p. 38, n. 46).

Notemos que en sendos diplomas burgaleses (SERRANO, Obispado, III, pp. 48, 140) tanto Munio González como su hijo Rodrigo Muñoz vienen denominados «condes asturicenses», por "condes asturienses» (de Asturias de Santillana). Es un error evidente. 
Enderquina Gutiérrez, que por otro lado se prueba pertenecer a la familia. Como ya apuntó Menéndez Pidal, en un interesante trabajo sobre la muerte del Infante García de Castilla, al conde Gonzalo Muñoz se le acusó de negligencia en la custodia del dicho infante, no ya de su muerte, el año 1026. Fue conde y gobernador o teniente en las Asturias de Santillana durante unos treinta años. Se cuenta de él que, hallándose enfermo de parálisis en Valladolid, se curó milagrosamente por la aplicación de una reliquia o escapulario que le mandó el santo abad de Oña, Iñigo (1034-1068), por medio de su esposa.

Su hijo Munio González, el padre de Jimena, fue uno de los principales colaboradores de Fernando I y de Alfonso VI en el gobierno y en la reconquista. Aparece esporádicamente en sus diplomas (dos veces sólo en los de Fernando I), quizás por la distancia de su tenencias. Alfonso VI concedió el título de conde y con él aparece en los actos solemnes del cambio de rito por los años 1080 y siguientes. Debió morir hacia 1085 . Nada extraño que el rey conociese a su familia, a su hija Jimena y de ella se enamorase.

Después de la muerte de su padre comienza a figurar en la corte regia Rodrigo Muñoz, que en 1105 es ya conde y cuyas memorias llegan hasta el año 1115. El obispo don Pelayo le hace figurar en el concilio de Oviedo celebrado ese mismo año 1115, entre los magnates venidos de las Asturias de Santillana, aunque no le da el título de conde.

Una hija de este conde, sobrina de Jimena, obtuvo un envidiable casamiento: nada menos que con el poderoso conde gallego Pedro de Traba, ayo y defensor del nieto de Alfonso VI, el futuro emperador Alfonso VII. Esta ilustre condesa tuvo con ese conde gallego una buena descendencia. Su nombre es Mayor Rodríguez ${ }^{(36)}$.

Por lo que mira a Urraca Muñoz, presunta hermana de Jimena, y a Enderquina Gutiérrez, no tenemos noticias directas y procedemos por deducciones. La esposa del conde Gómez González de Bureva, el íntimo colaborador de la reina Urraca en las luchas con Alfonso de Aragón, se llamaba Urraca Muñoz y era hermana de un poderoso conde, en expresión del Anónimo de Sabagún. Ese conde no puede ser otro que Rodrigo Muñoz ${ }^{(3)}$.

${ }^{36}$ La condesa Mayor Roiz o Rodríguez (por sobrenombre también Gontrodo en Galicia), aunque ignorada por los antiguos genealogistas, está bien documentada en Jubia, Santiago y Sahagún. En diploma de Jubia, fecha 26 diciembre 1113, aparece ya casada con el conde Pedro Froilaz de Traba, ayo de Alfonso VII (MONTERO, Jubia, p. 69, n. 19). Y en diploma de Sahagún, fecha 3 mayo, 1126, hace una donación por el alma de su marido y recuerda el nombre de sus hijos propios: Rodrigo, Velasco, García, Toda, Urraca, Sancha, Elvira y Alduara (EsCALONIA, Historia, p. 518, n. 152). Aparece también en Oña (ARGÁIZ, Soledad, VI, 455).

37 La esposa del conde Gómez González de Bureva (m. en Campo de la Espina, 1110) está muy poco documentada. Al fin conocemos su nombre y su apellido: Urraca Muñoz. Los 
De Enderquina Gutiérrez se conserva un precioso pergamino original: dona ella a la iglesia de Burgos, "a la cual todos los nobles Cántabros tienen por propia madre», su heredad y la de su hermano Rodrigo Gutiérrez en Tajadura. El acta es confirmada por todos los nobles del palacio de la reina doña Urraca. Se confiesa ella esposa del conde Suario (Vermúdez). Con mucha probabilidad es hija de Gutierre Muñoz, el hermano de Jimena ${ }^{(38)}$.

\section{d) Alegaciones en contra y en favor de esta filiación}

Quintana Prieto ha presentado a favor de la berciana Jimena Muñiz una prueba que parece irrefutable: la tenencia del castillo de Ulver, en la ribera del Bierzo, territorio que más tarde será el honor o dote de su hija la infanta Elvira. Este autor afirma que allí nació y vivió Jimena y de allí eran su padres.

Pero aquí está el punto débil de su argumentación: no se prueba que en el Bierzo gobernase un famoso conde llamado Munio. Quintana hace padre de Jimena unas veces al conde Munio Muñiz el de Sevilla, y otras al mismo Munio González de Cantabria. Ni uno ni otro estuvieron radicados en el Bierzo.

Por otro lado nada prueba que esa Jimena Muñiz tuviese la propia hacienda en el Bierzo, fuera de esa tenencia, otorgada por el rey. La única donación que de ella conocemos se refiere a una finca comprada a sus poseedores. ¿Esa Jimena Muñiz teniente del castillo de Ulver no pudo ser la misma Jimena Muñoz de Cantabria? Yo creo que sí. Aun residiendo ella en su tierra natal pudo tener en dicho castillo su vicario ${ }^{(39)}$.

apunta su propio hijo, el conde Rodrigo Gómez de Bureva, en una donación a San Pedro de Dueñas, fecha 17 junio 1126: «Ego Rodrigo Gomez, filius comitis Gomez Gonzalviz et filius comitisse Urrache Moniuz». San Pedro de Dueñas (León), A del monasterio OSB, mss. n. 12 (copia siglo XII). Ver También: SERRANO, Obispado, III, p. 129, n. 66.

El Anónimo de Sahagún escribe: «E el inventor e inflamador de esta mentira e falsedad fue uno llamado Beltrán, al cual llamaban conde, por cuanto había traído por mujer a la que había sido mujer del conde Gómez, la cual descendía de muy noble e real generación» (Crónicas, ed. Ubieto, p. 68, n. 36, ed. Escalona, p. 318).

${ }^{38}$ Ver supra nota 35. Por la documentación de Oña y de Espinosa sospechamos que la condesa Enderquina es de esta familia. Ver: ARGÁIZ, Soledad, VI, 455, 536.

${ }^{39}$ A favor del origen leonés y berciano de Jimena Muñoz se suele traer, ya desde Sandoval, el texto del epitafio de San Andrés de Espinareda. ¿Qué grado de fe nos merece ese epitafio? Yo lo dataria de fines del siglo XII o comienzos del XIII. Esa lápida pizarrosa y oscura se halla hoy en León, Museo Arqueológico Provincial (Edificio de San Marcos). El texto me merece muy poca fe. El hecho de hallarse en ese cenohio leonés tampoco obliga a creer que ahí esté enterrada la princesa. Hay otros ejemplos que nos aleccionan para ser cautos. Por otra parte carecemos de la documentación necesaria, ya que ese archivo pereció en un incendio. 
O bien, esa Jimena Muñiz no tuvo nada que ver con la infanta Elvira, y el rey Alfonso VII o su madre la reina Urraca dieron a esa infanta la Ribera de Bierzo, que formaba parte del Infantado, como un honor gratuito.

A favor de la Jimena Muñoz de Cantabria yo presentaría tres argumentos: el celibato, la familia y la herencia.

De Jimena Muñoz nos consta positivamente su celibato, que era la condición más aconsejable en una amada del rey; de Jimena Muñiz, no nos consta.

La familia de esa dama berciana no es bien conocida, en cambio es muy conocida la familia de la dama cántabra y resulta ser una de las más nobles de reino. La dama amada por el rey era nobilissima, para el obispo Pelayo, y muy noble para el Anónimo de Sabagún.

Siempre nos sorprendió que los hijos del conde Osorio Martínez de León tuviesen derechos en la abadía de Aguilar de Campóo, al lado de los condes de Lara. Pero ahora veo que les pudieron venir precisamente por una hija de Jimena Muñoz, la misma infanta Elvira, madre del dicho conde Osorio ${ }^{(40)}$.

Sorprende también que en diploma del año 1127 aparezcan juntas tía y sobrina, es decir la condesa Mayor Roiz y la «infanta» Jimena donando sus heredades a Santa Eulalia de Castañeda, como afirma Argáiz. Si las hijas de Jimena Muñoz, Elvira y Teresa Alfonso, llevaron el título de infantas, aun siendo ilegítimas, no nos sorprenda que también su madre lleve el mismo título. Recordemos que, según la Chronica Adephonsi Imperatoris, Jimena fue muy amada del monarca, valde dilecta ${ }^{(41)}$.

\section{e) La infanta Elvira Alfonso, bija de Jimena Muñoz}

Las relaciones amorosas entre Alfonso VI y Jimena Muñoz debieron tener lugar, muy probablemente, como ya es sabido, entre los años 1077 y 1079, después de la separación de Inés y antes del matrimonio con Constanza. De este modo las dos hijas, nacidas de este amor, pudieron ya desposarse con los príncipes europeos antes de finalizar el siglo. La vida de Teresa es ya bien conocida, gracias a los estudios de los historiadores portugueses, sus vasallos. No así la de Elvira, que recién casada salió de su patria y se embarcó luego en la cruzada a Tierra Santa con su marido el conde de Tolosa.

40 J. GonzÁlez, El Reino de Castilla en la época de Alfonso VIII, Madrid 1960, p. 544. C. MERCHÁN FERNÁNDEZ, Sobre los origenes del régimen señorial en Castilla, Málaga 1982, pp. 272,278, n. $1,7$.

${ }^{41}$ Ver Apéndice Documental. 
Ya en nuestros días se le dedicaron dos artículos intentando rastrear, a base de la documentación y ante el silencio de las crónicas, sus andanzas después de la dicha cruzada. Se ha descubierto que, dejando a su único hijo en Francia, como heredero del condado paterno, retornó a su tierra natal, creando un nuevo hogar, ya que su primer marido había muerto allá en Palestina.

Tres hijos tuvo de este nuevo enlace, que llevaban el apellido Fernández, indicando que Fernando era su padre, un padre enigmático, desconocido. Ahora, gracias al diploma que él mismo expide en favor de la abadía de Cluny, el año 1117, conocemos bien su identidad. Es Fernando Fernández, hijo del conde Fernando. Por otro privilegio de la iglesia de Astorga, del año 1130, sabemos que era conde, consul Malgradiense, de Benavente ${ }^{(42)}$.

Por ser conde en este lugar y por estar enterrado en Carrión de los Condes, en San Zoilo, podemos presumir que su madre fue Aldonza Gómez, hija de los fundadores de ese convento carrionense ${ }^{(43)}$.

Fue muy apreciado por la reina Urraca y por su hijo Alfonso VII, que le otorgaron el título condal y le admitieron en el séquito palatino. Debió morir poco después de ese año 1130. De sus tres hijos, García, Diego y Teresa Fernández, la más notable fue la última, que contrajo matrimonio con el ilustre conde leonés Osorio Martínez, cabeza de los Osorio y los Villalobos ${ }^{(44)}$.

De regreso a su patria, a su tierra natal, Elvira fue bien recibida por su hermana la reina Urraca, y por el joven rey Alfonso VII. En la primavera del año 1115 asiste ya con los reyes al concilio de Oviedo. El enlace matrimonial

${ }^{42}$ El diploma de 1117, verlo aquí en el apéndice. Por su parte, Quintana Prieto (Temas bercianos, III, 343), además de darnos una interesante biografía de la infanta Elvira, nos da el regesto del documento del año 1130.

En los diplomas de la reina Urraca y de su hijo Alfonso VII, aparece varias veces "comes Fredenandus in Campos». El año 1129 Alfonso VII refrenda las donaciones de Fernando I a Santa Marta de Tera, «cum consensu et voluntate comitis domni Fredenandi», lo que es índice de su gran estima hacia el conde (E.S., 16, 479, n. 25).

Ya Sandoval nos transcribió el texto de su epitafio (Historia, p. 205):

Pulvis in bac fossa pariter tumulantur et ossa consulis illustris Ferdinandi Malgradiensis.

En la documentación de la segunda mitad del siglo XII (Fernando II, Alfonso IX) aparece el magnate Fernando Rodríguez de Malgrado, que pudiera ser nieto de nuestro conde, hijo del «senior» Rodrigo Fernández de Valderas.

${ }^{43}$ Sospecho que el conde Fernando es hijo de la condesa Aldonza Gómez de Carrión (hija del conde Gómez Díaz y Teresa Peláez). En una donación a San Román de Entrepeñas, año 1087 (AHN, Clero carp. 1740, n. 7), ella nombra a sus hijos Fernando Fernández y Elvira Muñoz. Su padre pudo ser el conde gallego Fernando Mitiz.

${ }_{44}$ J. M. Canal SánChez-Pagín, El Conde Osorio Martínez y los marqueses de Astorga, en "Astorica», n. 7 (1988) 11-31. 
con Fernando pudo realizarse entre esta fecha y el año 1117 , año de la donación a Cluny. Pero ella no sólo contaba con la hacienda propia de su marido, sino que había recibido de los reyes su propia herencia, la que le competía como hija de Alfonso VI ${ }^{(4)}$.

En 1124 hace una donación personal en pro de la alberguería fundada por Vermudo Pérez, aportando su herencia en Corvillos. El año 1129 la vemos ya honrada por el rey con la tenencia de Bolaños, Castroverde y Villarejo, en Tierra de Campos. Al mismo tiempo aparece con la tenencia de Valderas el "senior» Rodrigo Fernández, su posible hijastro, es decir, un hijo de Fernando Fernán$\mathrm{dez}$, habido en un primer matrimonio. Más tarde veremos a su yerno, el conde Osorio, dominando en esta fértil Tierra de Campos, que al menos parcialmente era también tierra y feudo de su propio marido.

Desde 1133 hasta 1156 Elvira es también teniente en la Ribera del Sil, en el Bierzo. ¿Eran los dominios de su madre Jimena Muñoz? ¿Fue una gracia personal del rey Alfonso VII? Lo ignoramos.

Su muerte debió ocurrir hacia 1158, casi al mismo tiempo que la de su sobrina la infanta Sancha Raimundi.

\section{ACLARACIONES Y CONCLUSIONES}

Resta ahora hacer algunas aclaraciones al título de este trabajo, y poner en relieve algunas conclusiones afloradas en el decurso del mismo. $Y$, en primer lugar, las aclaraciones:

1.' Decimos Jimena Muñoz y no Muñiz ni mucho menos Núñez. Tanto el obispo de Oviedo como la Crónica del Emperador escriben Xemena Munionis. Es decir Jimena, hija de Munio. En el latín medieval Munio es diferente de Nunno. Algunos autores modernos opinan en cambio que tienen ambas palabras el mismo valor y significado, y que se pueden aplicar sin distinción a la misma persona. Menéndez Pidal castellaniza Munio en Muño. Aquí se deja igual ${ }^{(46)}$.

Munio, Munionis a veces se convierte en Munius, Munii. De ahí que en

45 Qintana Prieto, Temas Bercianos, III, 277-416. La otra hija de Alfonso VI, llamada también Elvira, mujer de Rogerio II de Sicilia, se casó hacia 1117 y murió en Sicilia hacia 1140.

${ }^{46}$ A comienzos del siglo XVII escribía el clásico fray Antonio de Yepes, OSB: «El término de Muño o Munio o Nuño fue antiguamente muy celebrado en Asturias, y en los privilegios que concedían los reyes andan muchos con ese apellido firmando las escrituras como grandes y principales del reino" (Crónica de la Orden de San Benito, cap. 159: BAE, t. 125, pp. 23-24). El padre Carballo por su parte escribe Munión (Antigüedades, p. 290). 
Castilla haya prevalecido el uso del apellido Muñoz (de Munionis o Munioz), y en el reino de León el uso de Muñiz (de Munii).

A su vez Nunno, Nunnonis se hace Nunnus, Nunni, y de ahí el apellido Núñez, en ambos reinos.

2." Decimos amiga de Alfonso VI y no amante del rey. El citado Menéndez Pidal, que tiene otras opiniones al respecto, habla de «la reina Constanza y la amante del rey», de aquella «hermosa francesa, parienta de la novia, que tuvo a fortuna, el agradar más que esta al rey».

A la joven Jimena Muñoz que, al tiempo de las relaciones con el monarca, contaría unos dieciocho abriles, podemos denominarla manceba, concubina o amiga del rey, pero no amante en el sentido moderno de esta palabra, cargada de peyorativos. No fue ella quien tomó la iniciativa, y le sería difícil negarse a los deseos del rey, que venía con cierto derecho de pernada.

En segundo lugar reproducimos aquí las principales conclusiones:

1." La mujer de perdición, con quien Alfonso entabló un ilícito connubio (matrimonio), no fue Jimena Muñoz, sino la misma reina Constanza, dado que el rey y la primera mujer, Inés de Aquitania, se hallaban separados. El primer matrimonio fue anulado. Es cierto.

2." Jimena Muñoz no pudo ser hija del conde Munio Rodríguez y su esposa Jimena Ordóñez. Aunque la cronología no lo impida, es muy difícil que Alfonso VI tuviese relaciones con una hija de ese conde que había sido un tirano para su padre Fernando I.

3." Que sea hija del conde asturiano Munio Muñiz, el de la jornada de Sevilla, es muy poco probable, ya que lo calla el monje de Corias. Le damos sólo un $5 \%$ de probabilidad.

4." Que sea hija del conde cántabro Munio González y hermana del conde Rodrigo Muñoz, lo creemos mucho más probable por las circunstancias apuntadas. Le damos un $25 \%$ de probabilidad.

5." Su hija, la infanta Elvira Alfonso, después de la Cruzada a Jerusalén y viuda ya del primer esposo, el conde de Tolosa, retornó a su patria y se desposó de nuevo con Fernando Fernández, que más tarde fue conde, con el cual tuvo tres hijos. La hembra, Teresa Fernández, se casó a su vez con el conde leonés Osorio Martínez, y fueron cabeza de la ilustre Casa noble de los Osorio y de los Villalobos.

Jose M.' CANAL SÁNCHEZ-Pagín León 


\section{BIBLIOGRAFIA}

ARGaíz, Gregorio, OSB, La Soledad laureada, VI, Madrid 1675.

BRUel, A., Recueil des chartes de l'abbaye de Cluny, Paris 1888-1894, 6 vols.

CANAL SÁNCHEZ-PAGíN, J.M., La Infanta doña Elvira, hija de Alfonso VI y Gimena Muñoz a la luz de los diplomas, en Archivos leoneses, n. 66 (1979) 271-287.

Carballo, L.A. de, SI, Antiguiedades y cosas memorables del Principado de Asturias, Madrid 1695, 470 pp. Reimpresión, Gijón 1988.

- Linajes asturianos, Gijón 1987, 200 pp. Ed. J.M. Patac, SI.

D'ANTINE, F.M., CLEMENCET, Ch., DURAND, U., L'Art de vérifier les dates des faits bistoriques, 3.' ed. Paris 1783, 3 vols. (Obra de los Padres Maurinos, que aún conserva valor).

David, P., Études historiques sur la Galice et le Portugal, Paris 1947.

DefourneaUX, M., Les Fransais en Espagne aux XI et XII siècles, Paris 1949.

Del Álamo, J., SI, Colección diplomática de San Salvador de Oña, Madrid 1950, 2 vols.

Díez Herrera, Carmen, El Dominio de Santa Maria del Puerto en la Edad Media, en Cuadernos de Trasmiera, I, Santander 1988.

ESCALONA, R., OSB, Historia del real monasterio de san Benito de Sabagún, Madrid 1782, 694 pp. Reimpresión León 1982.

FERNÁNDEZ DE BETHENCOURT, F., Historia genealógica y heráldica de la monarquia española, 10 vols. Madrid 1897-1920.

Ferreras, Juan de, Historia de España, Parte V, Madrid 1720.

FITA, Fidel, SI, La Conjuración del monje Roberto, en BRAH, 49 (1906) 326 y ss.

FLÓREZ, E., Memorias de las reinas católicas, 2." ed. Madrid 1770, 2 vols.

FloRiano CumbreÑo, A., El Monasterio de Cornellana, Oviedo 1949.

- El Libro Registro de Corias, Oviedo 1950, 2 vols.

- Colección diplomática del monasterio de Belmonte, Oviedo 1960.

GaRCía Álvarez, M.R., La Infanta Fronilde, peregrina a Compostela, en «Compostellanum», 9 (1964) 173-195.

GarCía GuineA, M.A., El Románico en Santander, 2 vols. Santander 1979.

García larragueta, S., Colección de documentos de la catedra! de Oviedo, Oviedo 1962.

Herculano, A., Historia de Portugal, 8.' ed., Lisboa (c. 1920), 6 vols. en 8.

HERRERO DE LA FUENTE, Marta, Colección diplomática del monasterio de Sahagún, III, León 1988.

JUSUE, M., Libro de Regla. Cartulario de Santillana del Mar, Madrid 1912.

MARRIER, M., Bibliotheca cluniacensis, Paris 1614, 1832 cols. 
Menéndez Pidal, R., El Romanz del Infant García, en Obras, II, Historia y epopeya, Madrid 1934.

- La España del Cid, 7." ed. Madrid 1979, 2 vols.

MONTERo DíAZ, S., Colección diplomática de San Martín de Jubia, Santiago 1935, $156 \mathrm{pp}$.

PÉReZ Bustamante, R., Señorio y vasallaje en las Asturias de Santillana (ss. XIII-XIV), Santander 1978, 244 pp.

QUiNTANA PRIETO, A., Jimena Muñiz, madre de doña Teresa de Portugal, en «Revista portuguesa de historia», 12 (1969) 223-260. Reproducido en Temas Bercianos, Ponferrada, 1983, III, 213-254.

REILLY, Bernard F., The Kingdom of León Castilla under Alfonso VI (1065-1109), Princeton, N.J. (USA), 1988, XX-406 pp.

Notar que esta obra la he conocido después de redactado este trabajo, que queda inmutado.

ROBERT, U., État des monastères espagnols de l'ordre de Cluny aux XIII-XV siècles, en BRAH, 20 (1892) 321-431.

SAlAZAR ACHA, J. de, Una Familia de la alta edad media: los Velas y su realidad bistorica, en «Estudios genealógicos y heráldicos» 1, Madrid 1985, 19-64.

SANDOVAL, Fray P. de, Historia de los reyes de Castilla y de León, 2." ed. Madrid 1792 (1.' ed. Pamplona 1615).

Serrano, L., OSB, El Obispado de Burgos, 3 vols., Madrid 1935.

Serrano SanZ, M., Cartulario de Santa María del Puerto (Santoña), en BRAH, 73 (1918) 420-442, 74 (1919) 19-34, 224-243, 323-355, etc.

- Cronicon Villarense. Liber regum, en BRAEsp., 6 (1919) 192-220.

SOTA, Francisco, OSB, Crónica de los Principes de Asturias y de Cantabria, Madrid 1681. 


\section{APÉNDICE DOCUMENTAL}

\section{A. TEXTOS HISTÓRICOS}

1) Inés de Aquitania, primera esposa de Alfonso VI

«Anno 1069 coenobium Sancte Mariae de Karitate incohatum est... His diebus Hildefonsus, rex Hispanorum, duxerat filiam Guidonis, comitis ducis Aquitanorum, quam habuit de Mateode, uxore suprascripta. Pro qua re extitit causa et contentio de lege Romana. Quam legem Romana voluit introducere in Hispaniam, et Toletanam mutare. Et ideo fuit factum bellum inter duos milites, et falsitate fuit victus miles ex parte Francorum.

Anno 1070 domnus Guaterius abbas dormivit in pace, V. Idus Maii» (Cbronicon Sancti Maxentii sive Malleacense, ed. Bouquet, en Recueil des historiens des Gaules et de la France, XI, Paris 1876, pp. 216-221. La primera ed. en: Ph. Labbe SI, Nova Bibliotheca Manuscriptorum, II, Paris c. 1650, pp. 207 ss.).

2) El papa Gregorio VII reprende la conducta matrimonial de Alfonso VI

"At nunc, comperto quod diabolus tuae saluti, et omnium qui per te salvandi erant, more suo invidens, per membrum suum, quemdam Robertum pseudomonachum, et per antiquan adiutricem suam, perditam feminam, viriles animos tuos a recto itinere deturbavit..., nunc confundimur, erubescimus et contristamur...

Remove a te quantocitius consiliarios falsitatis... Non te a salutaribus monitis atque institutis nostris incestae mulieris amor abripiat...

Vires resume, illicitum connubium, quod cum uxoris tuae consanguinea inisti, penitus respue» (GREGORIO VII, Epistola a Alfonso VI, fecha 27 junio 1080, ed. J. Migne, PL, 148, 604-606. E. Caspar, Das Register Gregors VII, en MGH, en 8.', Epistolae selectae, II, Berlin 1920. D. MANSILlA, La Documentación pontificia basta Inocencio III [Monumenta Hispaniae Vaticana, S. Reg., 1], Roma-Burgos 1955, 33-34. Este autor le asigna la fecha, Ceprano, 27 junio 1080, por su posición en el Registro Vaticano. Otras ediciones en las colecciones conciliares de la Iglesia).

\section{3) Teresa, reina de Portugal, bija ilegítima}

"Qui etiam (Alfonso VI) Toletum, maximam urbem eorum, suo subiugavit imperio. Hic filiam Roberti ducis Burgundiorum duxit in uxorem, nomine Constantiam, de qua suscepit filiam, quam in matrimonium dedit Raimundo comiti, qui comitatum trans Ararim tenebat.

Alteram filiam, sed non ex coniugali thoro natam, Ainrico, uni filiorum filii eiusdem ducis Roberti, dedit. Hosque ambos in ipsis finibus Hispaniae contra 
Agarenorum collocavit impetum" (Ex Historiae Francicae fragmento, ab Hugone Florianensi Monacho scripto, ed. Fr. Du Chesne, Historiae Francorum Scriptores coaetanei, IV, Paris 1636-1649, p. 88; ed. Bouquet, Recueil des historiens des Gaules et de la France, XII, Paris 1877, p. 2).

\section{4) Teresa, reina de Portugal, era bija ilegítima}

«Sobre todo es de saber que el rey don Alfonso (VI), de noble memoria, mientras que él viviese, de una manceba, pero bien noble, había engendrado una fija llamada Theresa, la qual él había ayuntado en matrimonio a un conde llamado Enrique, que venía de la noble e real sangre de Francia" (Crónicas anónimas de Sabagún, 25, ed. A. Ubieto Arteta, Zaragoza 1987, p. 38. Ed. R. Escalona, Historia de Sahagún, p. 306, cap. 21).

\section{5) Esposas legítimas y concubinas de Alfonso VI}

«Hic habuit quinque uxores legitimas: primam Agnetem, secundam Constanciam reginam, ex qua genuit Urracam reginam, coniugem comitis Raimundi, de qua ipse genuit Sanciam et Adefonsum regem; tertiam Bertam, Tuscia oriundam, quartam Elisabeth, ex qua genuit Sanciam, coniugem comitis Roderici, et Geloiram, quam duxit Rogerius, dux Siciliae; quintam Beatricem, quae, mortuo eo, repedavit in patriam suam.

Habuit etam duas concubinas, tamen nobilissimas: priorem Xemenam Munionis, ex qua genuit Geloiran, uxorem comitis Raimundi Tolosani, patris ex ea Adefonsi Iordanis, et Tarasiam, uxorem Henrici comitis, patris ex ea Urracae, Geloirae et Adefonsi. Posteriorem nomine Ceidam, filiam Abenabeth, regis Hispalensis, quae baptizata Elisabeth fuit vocata, ex hac genuit Sancium, qui obiit in lite de Ocles» (PELAYO OBISPO DE OVIEDO, Chronica regum, ed. Flórez, en ES, t. 14, 474-475. Ed. E. Sánchez Alonso, Madrid 1924, p. 86).

\section{6) Águeda de Normandía, prometida de Alfonso VI}

«Porro Agatha, regis (Guillemli I) filia, quae prius fuerat Heraldo desponsata, postmodum Amfurcio (Adefonso), regi Galliciae, per procos petenti, missa est desponsanda. Sed quae priori sponso ad votum gavisa non est, secundo sociari valde abominata est. Anglum viderat et dilexerat, sed Ibero coniungi nimis metuit, quem nunquam perspexerat... Oravit et exaudita est, oniterque virgo defuncta est» (ORDERICO VITALIS, Historia ecclesiástica, V, 13: PL 188, $414 \mathrm{~A}$ ).

\section{7) Águeda la prometida}

«Alterius (Agathae) quae Aldefonso, Galliciae regi, per nuncios iurata, vigineam mortem impetravit a Deo. Repertus in defunctae genibus callus, crebrarum eius orationum index est" (GUILLERMO DE MALMESBURY, De Gestis regum Anglorum, III, 276: PL 179, 1253 A).

8) Elias, conde de Le Mans, se casa con Inés, antigua esposa de Alfonso VI

"Defuncta coniuge sua (Matilde), coelibem vitam actitare renuit, sed Agnetem, filiam Guillelmi, Pictavorum ducis, relictam Hildefonsi senioris, Galliciae 
regis, uxorem duxit. Celebres nuptias cum ingenti tripudio perpetravit, sed sequenti anno, multis lugentibus, obiit» (ORDERICO VITALIS, Hist. eccl., X, 14: PL 188, 757 A).

9) Teresa, reina de Portugal, bija ilegítima

"Ipsa autem Tarasia erat filia regis domini Adefonsi, sed non de legitima sed de concubina, valde tamen a rege dilecta nomine Xemena Munionis, quam rex, dilectionis et honoris causa, dedit maritatam Henrico comiti, et dotavit eam magnifice, dans Portugalensem terram iure hereditarion (Chronica Adefonsi Imperatoris, ed. L. Sánchez Belda, Madrid 1950, p. 58, núm. 73 Ed. Flórez, en ES, t. 21, p. 347, núm. 29).

\section{0) Mujeres de Alfonso VI}

«Este rei don Alfonso priso muller la Caida, qui era sobrina d'Avenalfage, $e$ baptizola e fo cristiana, e tovo en ella fillo al ifant don Sancho, al que dixieron Sancho Alfonso. Pues lo mataron moros en la batalla de Uclés.

E pues ovo el rei don Alfonso otra muller qui ovo nomne Xemena Munnioz, et ovo en ella dos fillas. La ifant dona Alvira et la ifant dona Teresa» (Liber regum, ed. M. Serrano Sanz, Cronicon Villarense, en «Bol. R.A.H.» 6 (1919) 210. Texto escrito en el primer decenio del siglo XIII, del cual depende la Crónica general de España, del conde Barcelos, ed. D. Catalán, Madrid 1971, I, p. 314).

B. REGESTO DE ALGUNOS DOCUMENTOS RELATIVOS A JIMENA MUÑOZ DE CANTABRIA Y A SU FAMILIA

1) 1082, agosto 13.

El conde Munio (González) dona al monasterio de Oña el monasterio de San Juan de Ovilla (Valle de Mena) y las iglesias de San Juan de Boo y de San Esteban de Cudón (Torrelavega).

Publ:: Del Álamo, Oña, I, p. 111, núm. 76.

2) 1085, junio 22 .

Rodrigo Muñoz y su hermana Jimena Muñoz donan a Santa María del Puerto (Santoña) su heredad en Solórzano.

Publ.: Serrano SANZ, Santa Maria del Puerto, p. 29, núm. 33.

3) 1089, abril.

El conde Fernando (Díaz de Oviedo) y su esposa Henderquina donan al presbítero Juan Paláez dos monasterios en el valle del río Pionia (Pigüeña).

Publ:: FloRiano, Belmonte, p. 65, núm. 4.

4) 1103, marzo 7 .

El conde Rodrigo Muñoz y su esposa Teresa donan a Santillana del Mar su heredad en Villa Oreña.

Publ.: JUSUE, Santillana, p. 80, núm. 62. 
5) 1113 , diciembre 26 .

Doña Gontrodo (Mayor) Rodríguez dona al monasterio de Jubia su heredad en Tresancos.

Publ.: MONTERO, Jubia, p. 69, núm. 19.

6) 1117 , julio 8 .

El magnate Fernando Fernández dona al monasterio de Cluny (Francia) su heredad en el monasterio de Ferreries (Lemos).

Publ:: BRUEL, Cluny, V. pp. 280-281.

7) 1120 , setiembre 20.

Jimena Muñoz, junto con sus sobrinos, y por el alma de (sus padres) el conde Munio y la condesa doña Mayor, y por el alma de (su hermano) el conde Rodrigo, dona al monasterio de Cluny el monasterio de Santa Cruz de Castañeda.

Publ.: BRUEL, Cluny, V, pp. 302-304.

8) 1121 , marzo 4.

La condesa Enderquina, esposa del conde Suario (Vermúdez), dona a la iglesia de Burgos su propia heredad, y la de su hermano Rodrigo Gutiérrez, en Tajadura.

Publ:: SeRrano, Burgos, III, p. 150, núm 81.

9) 1125 , febrero 27.

El conde Pedro (Froilaz de Traba) y su esposa Mayor (Gontrodo) donan a Jubia su heredad en Tresancos, Némitos, etc.

Publ.: MONTERO, Jubia, p. 76, núm. 30.

10) 1125 , marzo 24.

La condesa Mayor Rodríguez, hija del conde Rodrigo y de su esposa Teresa, dona a Sahagún la mitad de Santa María de Felechas, y toda su heredad en Villa Palacios (cerca de Burgos), que ella había recibido de sus padres.

Publ.: EsCALONA, p. 516, núm. 151.

11) 1127 , noviembre 4 .

La condesa doña Mayor, junto con su tía la infanta doña Jimena, dona a Santa Eulalia de Castañeda (Espinosa de los Monteros, Burgos) unas heredades próximas a esa iglesia.

Reg.: ARGÁIZ, Soledad, V. pp. 455 y 536 (Iglesias de Oña y de Espinosa).

12) 1130 , mayo 17.

El cónsul Malgradiense don Fernando, junto con su esposa la infanta Elvira y sus hijos, dona a la iglesia de Astorga la heredad de Fenolio, cabe el río Orbigo, por el alma de sus padres.

Reg.: B.N., Mss. n. 4357 (siglo XVII), Indice de las escrituras de la iglesia de Astorga, donde se hace el siguiente regesto: «Donación a favor de dicha santa Iglesia 
y su obispo don Alo, hecha por el cónsul don Fernando Malgradiense, por si y todos sus hijos, y su mujer la infanta doña Elvira, madre de estos, de la villa de Fenolio (Hinojo), cerca del río Orbigo, en tierra de Astorga, con todos sus términos, y pertenencias, que tuvo de sus padres y por otras adquisiciones, todo por remedio de su alma y (la de) sus parientes. Su fecha Nonas Maii, sub era quadragena octava et vicena, addita centena, preterita millena, que corresponde a 6 de mayo de 1130 , reynando en Toledo y León don Alfonso ( $7{ }^{\circ}$ de León). Confirmanla Monio Pelagii, mayordomo del rey, Joan Petri, Gutierre Eri, Diego Bermudi, Anaya Cidi, Martino Anaye, Pedro Didaci, el conde don Rodrigo, Osoriio Martini, et quasi todos los de aquella tierra: ommes fere illius terre etiam confirmant».

13) 1130, enero 23.

Jimena Muñoz dona al monasterio de Oña sus heredades sitas entre Argomedo y Petralata.

B. Real Academia de la Historia, Col. S. y C., 0-7, fol. 25 (siglo XVII), donde se da el siguiente regesto: «Sub Xti nomine et eius imperio. Ego Eximena Munioz nullo cogentis imperio, etc. Por el remedio de su alma y de sus padres, dona al monasterio de Oña toda su heredad que tiene en Argomedo usque in Petra Lata, in primis in Barcenilla illo solare... Noto die X Kalendas februarii. Era 1173, año ab Incarnatione Domini 1130" (sic).

Ver: OCEJA GONZALO, Isabel, Documentos del monasterio de Oña, (1032-1284), Burgos 1983, p. 40. La autora sugiere la fecha de 1131, pero posiblemente se trata de la era 1168 (MCLXVIII) que corresponde al año 1130, en vez de la era 1173 (MCLXXIII), que corresponde al año 1135.

\section{Textos Documentales}

1) 1085 , junio 22 .

Rodrigo Muñoz y su bermana Jimena Muñoz donan a Santa María del Puerto (Santoña) su beredad en Solórzano.

B. AHN, Códices, 1001-B (s. XII/1), f. 20v.

Publ.: Serrano SANZ, Santa María del Puerto, p. 29, n. 33.

Sub Christi nomine et eius imperio. Ego denique Rodrig Munnioz de spontanea mea voluntate sic placuit inter me et mea germana domna Eissemena, sic donamus vel concedimus pro remedio anime nostre, quantum ad nos pertinet in ipsa villa que vocitatur Solorceno: hereditatem nostram ab omni integritate, ad regulam Sancte Marie de Portum, et ad vos, abbas Martinus. Et de una parte est ipsam hereditatem circa rigo de Navanna et de alia parte pumare de Peretiello, carrera antiqua que discurrit de hazas de felguera, et alio pumare que est a la Petrosa. Et ego Rodrigo Muniioz et mea germana domna Eissemena sic damus ad vos, abbas Martinus et ad fratres tuos, ipsam quartam partem, quod ad nos pertinuit. Sic donamus vel 
confirmamus ad vos, abbas Martinus et ad atrium Sancte marie semper virginis ab omni integritate, ut in ipsa regula serviat ac permaneat iure perpetuo.

Quod si aliquis homo de hanc regulam ipsa hereditate iam superius dicta abstraere voluerit, aut ego Rodrico Munnioz aut ego Eissemena Munnioz, aut filiis aut neptis vel consanguinei, seu ex regia potestas, quisquis homo talia fecerit, pariet ipsa hereditate, vel ipsos pumares dupplatos vel triplatos cum fructibus suis ad ipsa regula Sancte Marie, vel ad abbate, et ad fratribus qui ibidem commoraverint in amorem Domini, et tres libras aureas, et ad regis terre IIII libras aureas. Et hanc scripturam firmis fiat.

Facta scriptura testamenti notum die, II feria, X kalendas iulii, in Era T. C. XX. III. Regnante rex Aldefonsus in regno. Et ego Rodrig Munnioz et Eissemena Munnioz, qui hanc scripturam traditionis vel venditionis fieri iussi, legente audivi et et de manu mea roborabi coram testes. Andres Miguellez, testis. Salvator Peitrez, testis. Petro Gonzalvez, testis.

Petro Sangez Verviensis scripsit.

2) 1117 , julio 8 .

Fernando Fernández, junto con su esposa la infanta Elvira Alfonso, hija de Alfonso VI, dona a San Pedro de Cluny (Francia) la cuarta parte del monasterio de (Santa Maria de) Ferreira de Pantón, en tierra de Lemos (Lugo).

A. Paris, B.N., Col. de Borgoña, 196, original.

B. Ibidem, Cartulario B de Cluny (s. XII) f. 28.

C. Ibidem, Col. Moreau, 283, f. 108.

Publ.: A. BRUEL, Recueil des chartes de Cluny, V, pp. 280-281.

In nomine Dei omnipotentis, qui omnia ex nichilo creavit, Patris et Filii et Spiritus Sancti. Amen. Quia presentem vitam sine peccato transire non possumus, et ad vitam eternam, nisi mundi pervenire nequaquam valemus, iubet Dominus Iesus Christus ut peccata nostra elemosinis redimamus, et de his que possidemus thesaurum in celis faciamus, quo fur non appropiat, neque tinea corrumpit. Et Paulus apostolus: «Dum tempus habemus, operemur bonum ad omnes». Et Salomon: «Rdemptio anime divitie sue». Et in libro Thovi: «Melius est elemosinam dare quam thesaurum auri reponere». Et, «qui facit elemosinam saciabitur vita». In qua elemosina non pauperum spolia sed propria Deo fiunt grata, quonian non placet Deo illud munus quod alter letus accipit et alter tristis amittit. Sed illa est Deo grata elemosina, que ex propria exhihetur hereditate vel substancia, non que de aliena datur rapina.

Igitur, in Dei nomine, ego Fernanz Fernanniz (sic), his et talibus doctus exemplis, necnon peccatorum meorum multitudine perterritus, et uxor mea infanta domna Gelvira, filia serenissimi regis Alfonsi, non coactus sed spontanea voluntate, placuit animo meo et predicte uxori mee, ut pro anima mea et anima patris mei Fernandi comitis, et anima uxoris mee, predicte infante, et pro animabus omnium aviorum et parentum meorum, facerem cartam vel testamentum, sicut et facio Deo 
et beatis apostolis Petro et Paulo, ad monasterium de Cluniaco, ubi domnus Poncius abbas esse videtur, de hereditate mea propria, quam habeo de patre meo et de avibus (sic) meis, iure hereditario, id est, quartam partem de monasterio de Ferreries, quod est positum in Gallecia, in terra de Lemos, iuxta Pantonem, totam quartam integram, sicut mihi competit, inter meos heredes, id est, casas, ecclesias, vineas, terras, populatas et non populatas, totamque hereditatem, per ubicumque eam invenire potuerint, ut fratres de Cluniaco, in predicto monasterio de Ferreries commorantes, quiete et hereditario iure in perpertuum possideant, ut predictorum apostolorum intercessionibus et fratrum de Cluniaco orationibus, omnia peccata mea, et uxori mee et patri meo et matri mee et omnibus parentibus meis, indulgeat omnipotens Dominus. Amen.

Nulli autem volumus fratres qui in Ferreries steterint servire nisi ad Cluniacum, sed abbas de Cluniaco ordinet et iudicet secundum ordinem suum sicut voluerit, et omnes qui post eum futuri sunt abbates, in secula seculorum. Amen.

Si quis autem de gente nostra vel extranea aut alius aliquis venire temptaverit et hunc testamentum irrumpere voluerit, in primis cum his qui Deum tradiderunt et crucifixerunt in inferno in perpetuum ardeat, et pro testamento quod voluit infringere auri libras $C$. persolvat, et quod inde auferre voluerit pariat in duplum vel triplum. Et hoc testamentum plenam et perpetuam habeat firmitatem.

Factum est autem hoc testamentum era $\mathrm{M}^{*} \mathrm{C}^{*} \mathrm{~L}{ }^{2} \mathrm{~V}$ *. VIII Idus Iulii, regnante Urraca regina cum filio suo Alfonso, Bernardo archiepiscopo in Toleto, apund sanctum Iacobum Didago secundo, apud Ovetum Pelagio episcopo, Petrus episcopus Lucensis, Didagus episcopus Auriensis.

Ego Fernanz Fernandiz et uxor mea infanta Gelvira hoc testamentum fieri rogavimus et manu propia roboravimus.

Gomes Pelaiz confirmat. Ferrandus Menendiz confirmat. Petrus Ovequiz confirmat. Cutz Gonzalvi confirmat. Gonzalvus Assuriz confirmat.

Citi testis et Beliti testis sumus et de manus nostras hoc roboravimus coram testes.

3) 1120 , setiembre 20 .

Jimena Muñoz, junto con sus sobrinas Sancha Roiz y Mayor Roiz, con los bijos de los condes Fernando y Enderquina, con el abad Pedro, por el alma del conde Munio y la de su esposa doña Mayor, por el alma del conde Rodrigo y por las almas de sus bermanos $y$ bermanas, y por el alma del abad Juan que junto con el conde Munio fundó este monasterio, dona a San Pedro de Cluny (Francia) el monasterio de Santa Cruz de Castañeda (Cantabria).

B. Paris, B.N., Col. Moreau, 283, f. 113.

Publ.: BRUEL, Recueil, V, pp. 302-304.

In nomine Domini et Salvatoris nostri Iesu Christi, quem iam venisse credimus pro salute hominis perditi, et iterum expectamus venturum ad iudicandum mun- 
dum, audiant presentes et futuri seriem huius descriptionis. Congruum quippe est et acceptabile Deo omnipotenti, ut quandiu in hoc corpore sumus et a Domino peregrinamur, aliquid operemur pro remedio anime nostre, que, corpore deficiente, vitam expectat inmortalem. Reminisci debemus Psalmiste dicentis quoniam «Vanitas est omnis homo vivens". Certe, que vanitas maior esse potest, quam vivere cum labore et suo creatori in presenti non obedire et post ad inferni claustra descendere? Est etiam alia conditio inter divites et pauperes constituta, quam pauperes in sua paupertate deficiunt. De divitibus scriptum est quia «Tesaurizant et ignorant cui congregant ea». Et iterum audivimus quia «Potentes potenter tormenta pacientur».

Propterea ego Semena Monios, sicul cum sobrinis meis Sancia Roiz et Maior roiz, et cum filiis comitis Fernandi et comitisse domne Enderquine et cum abbate domno Petro, pro animabus nostris et pro animabus comitis Monionis et uxoris sue comitisse domne Maioris, et pro anima comitis Roderici, et pro animabus fratrum nostrorum et sororum nostrarum, et pro animabus omnium aliorum parentum nostrorum, in hoc monasterio et in aliis monasteriis quiescentium, et pro anima abbatis Ioannis, et omnium parentum suorum, qui fundavit istud monasterium, simul cum comite domno Monione, decrevimus facere hoc quod sequitur.

Quoddam monasterium tenebamus iure hereditario Sancte Crucis consecratum, et in Castanneda, iuxta ripam Fluminis, quod vocatur Pisuenna. Nos ergo positi in Ispania, audivimus famam loci Cluniacensis et domni Poncii abbatis et sancte illius congregationis, qualiter constituti in Dei servitio, sub disciplina regulari vivunt, et ad celestia sine tedio tendunt. Propterea ego domna Semena, cum supradictis sobrinis meis tam viris quam mulieribus concedimus monasterium suprascriptum Sancte Crucis de Castanneda, cum omni integritate sua, et quantum ad ipsum locum pertinet, hoc est, monasterium cum villis suis, et cum suis antiquioribus terminis, scilicet montibus, collibus, silvis, pratis pascuis, atque paludibus, terras et vineas, cultas et incultas, ortos, molendinos, aquas, fontes, piscarias, introitus et exitus. Et sicut tenemus, ita de nostro iure tollimus et cartam testamenti facimus, et tradimus sacro altario beatorum apostolorum Petri et Pauli loci Cluniacensis, ita ut nullus ex nobis vel ex omni nostra progenie ibi partem aut rationem habeat vel requirat.

Et ita damus istum locum, ut non intret ibi saio ne pro homicidio, neque pro fossaderia, neque pro angaria regis. Ita damus sacro altario suprascripto, et tibi domno Poncio abbati et fratribus Deo ibidem servientibus, ut et nos viventes mereamur longevam salutem cum remedio animarum nostrarum, et requiem sempiternam parentes nostri possideant.

Vos autem exhortamur ut ab hodierna die et deinceps ipsum locum iure hereditario possideatis et habeatis licentiam de illo facere quodcumque volueritis. Quod si aliquis ex nostris vel extraneis, seductus mala cupiditate, in aliquo tempore hoc testamentum destruere voluerit, et hanc donationem irritam facere, pereat cum eis qui Dominum glorie crucifixerunt in eterna dampnatione, et pro damno temporali C libras auri persolvat, et quod facere ausus est nullo modo valeat, et testamentum presens roboretur in secula seculorum.

Facta series huius scripture II feria, XII Kalendas octobris, era C. LVIII post $\mathbf{M}$. 
regnante regina Urraca in Legione et filio suo Ildefonso in Toleto, Bernardo archiepiscopo in Toleto, Didaco episcopo in Legione, Pelagio episcopo in Oveto, Petro episcopo in Palentia, Semeno electo in Burgis. Et Ego, Semena Monios, simul cum sobrinis meis suprascriptis, hanc cartam testamenti, postquam fieri iussimus et legere audivimus, manibus nostris signantes roboravimus.

Comes Petrus Eldara (de Lara?) cf. Comes Suarius cf. Alfonso Fannis cf. Gonsalvo Gonsalviz cf. Petro Roiz cf. Gutierre Roiz cf. Monio Diaz cf. Martin Alfonso cf. Fernando Alvarez cf. Abbas Martinus de Sancta Iuliana cf. Abbas Alfonsus de Sancte Emeterii cf. Abbas Martinus de Sancta Maria de Portu cf.

Citi et Belit teste. Martinus Salvatoris scripsit.

\section{RÉSUMÉ}

Alphonse VI fut sans nul doute l'un des meilleurs rois de Castille (il fut, aussi, roi de León) (1071-1109). Pour cette raison il est intéressant d'étudier tous les aspects de sa personne et de sa vie. Le thème de sa famille, de ses femmes, a été très peu traité. Il s'agit d'identifier ici sa "très noble maîtresse ou amie», avec laquelle il eût deux filles: Thérèse, reine du Portugal, et Elvire, épouse de deux maris légitimes: le comte de Tolosa et le comte Fernando Fernández de Campos. Cette amie fut Jimena Muñoz, fille du conte de Cantabria, Munio González et soeur du conte Rodrigo Muñoz et de Urraca Muñoz, l'épouse du comte Gómez González de Candespina, que l'on traitait aussi de «très noble». Jimena n'a pas pu être fille du comte Munio Rodríguez de Galicia ni de sa femme Jimena Ordóñez ni du comte asturien Munio Muñiz, rendu fameux à la journée de Séville.

\section{SUMMARY}

Alfonso VI has been, without doubt, one of the greatest kings of Castilla (he was also king of León) (1071-1109). This in the reason why it is interesting the study of his life, his person and his family, his women. The theme of his women and his family has not been studied properly. We tray here to identify the «most noble concubine or friend" of Alfonso VI. He had two daughters with her: Teresa, queen of Portugal, and Elvira, spouse of of two legitimate husbands, the count of Tolosa and the count Fernando Fernández de Campos. This friend was Jimena Muñoz, daughter of the count of Cantabria, Munio González, and sister of the count Rodrigo Muñoz and of Urraca Muñoz, the wife of the count Gónez González de Candespina, also qualified as «most noble». Jimena could not be daughter of the count Munio Rodríguez de Galicia and of his wife, Jimena Ordóñez, neither of the count from Asturias Munio Muñiz, the one of the days journey of Sevilla. 